\title{
Skeletal abnormalities of acrogeria, a progeroid syndrome
}

\author{
A. Ho, M.D. ${ }^{1, *}$, S.J. White, M.D. ${ }^{1}$, and J.E. Rasmussen, M.D. ${ }^{2}$ \\ Departments of ${ }^{1}$ Radiology (Section of Pediatric Radiology) and ${ }^{2}$ Dermatology, University of Michigan Medical Center, \\ Ann Arbor, Michigan, USA
}

\begin{abstract}
We report the skeletal abnormalities in a 4 1/2-year-old boy with acrogeria, a progeroid syndrome of premature aging of the skin without the involvement of internal organs seen in Hutchinson-Gilford progeria syndrome. Acro-osteolysis of the distal phalanges, delayed cranial suture closure with wormian bones, linear lucent defects of the metaphyses, and antegonial notching of the mandible are the predominant skeletal features of the disorder. The skeletal features described in 21 other reported cases of acrogeria are summarized.
\end{abstract}

Key words: Acrogeria - Gottron acrogeria - Premature aging syndrome - Progeroid syndrome Progeria

Acrogeria was first described by Gottron in 1941 when he observed premature aging of the skin localized to the hands and feet, present from birth in two siblings [12]. Since then, there have been 19 reported cases of acrogeria, most of them in the European literature $[1-5,8,12-20,25,27,30$, 32] (Table 1).

Females are predominantly affected; only four males have been described $[4,12,14,20]$. Most patients are short; however, others are normal in height. Micrognathia is a prominent feature and many of the cases are described as having a pointed and pinched nose [11].

The hallmark of this condition is thin, wrinkled

* Current address: Samaritan Health Center, 5555 Conner Avenue, Detroit, MI 48213, USA

Address reprint requests to: S.J. White, Department of Radiology, Section of Pediatric Radiology, University of Michigan Hospitals, C.S. Mott Children's Hospital C3123, 1500 E. Medical Center Drive, Ann Arbor, MI 48109-0252, USA skin with mottled pigmentation, telangiectasia, and prominent veins over the upper trunk and dorsa of the hands and feet [11]. Histologically, there is atrophy of the dermis and subcutaneous fat [14]. The collagen fibers are loose and sparse, and the elastic fibers are often fragmented [16]. The epidermis is spared. The nails are often dystrophic or thickened; however, the hair is usually normal [11].

Although these patients have facies similar to patients with progeria, they do not share the poor prognosis associated with progeria. They do not develop severe generalized atherosclerosis, myocardial disease, or coronary artery disease. They can expect a normal life span with the same risk of atherosclerosis as the general population [11].

Although the condition of acrogeria is present from birth, it may not be recognized in the first 2 years. It can, however, be diagnosed before the patient reaches puberty [11]. The inheritance has been listed as autosomal recessive in McKusick's catalogue, Mendelian inheritance in man [23]. Gottron's original report concerned two siblings [12]; Groot et al's cases were a mother and son [14]. However, there are too few cases to be certain of the mode of transmission.

In previous reports, little emphasis has been placed on describing the skeletal findings accompanying this disorder. We here describe the skeletal features of acrogeria in our patient and summarize the radiologic findings in previously reported cases.

\section{Case history}

A 14-month-old white boy presented to medical attention with a history of being unable to pull himself up to stand from a sitting or prone position. His developmental history was otherwise normal. He walked at 12 months, and had normal fine motor skills. His social and language development were normal. 
Table 1. Summary of skeletal findings in reported cases of acrogeria (by chronological order)

\begin{tabular}{lll}
\hline 1941 & Gottron (1 and 2) & Small, but normally proportioned hands and feet; mandibular hypoplasia \\
1951 & Gromzig & Cortical thickening; widening of distal ends of bones \\
1955 & Bazex and Dupre & No radiologic description \\
1957 & Calvert & Normal \\
1957 & Morris & None reported \\
1959 & Laugier et al. & Ankylosis of interphalangeal joints in hands \\
1960 & Gruneberg & Bone age - normal \\
1961 & Lamy et al. & Congenital dislocation of hip noted at 18 months. Later sequelae of congenital \\
& dislocation \\
1961 & Volpato & Slight demineralization of bone; bone age and skeletal X-rays normal \\
1961 & Bommer et al. & Micrognathia, normal bone age \\
1961 & Batschvaroff et al. & Micrognathia, small hands and feet \\
1965 & Elefant et al. & Wide sagittal suture and lambdoid suture; enlarged posterior fontanelle; \\
& & bilateral congenital dislocation of hip; slight deformity of proximal radii \\
1970 & Levi et al. & Hourglass deformity of distal phalanges in hands and feet; shortening of right \\
& femoral neck; hypoplasia of left iliac wing; micrognathia; normal bone age \\
1970 & Butenandt and Christophers & Scuptured nose; small midface; broad metaphyses \\
1970 & Groot et al. & Mother: craniostenosis; hypoplasia of mandible, maxillae; \\
& & hypoplasia of terminal phalanges of hands; absent distal phalanx of 3rd toe \\
1971 & Raffi et al. & Son: normal skull; normal hand and foot X-ray \\
1972 & Rosenberg et al. & Gracile metacarpals; slightly short forearm on right; \\
1974 & Laurent and Agache & bilateral hallux valgus \\
1974 & Gilkes et al. & So X-ray findings \\
1977 & Hjortshoj and Heydenreich & No X-ray findings \\
\hline
\end{tabular}

He was the product of a full-term pregnancy in a 19-yearold woman. Birth weight was $2.7 \mathrm{~kg}$. At the time of evaluation, his weight was $9.36 \mathrm{~kg}$ (10th percentile), his height was $75.2 \mathrm{~cm}$ (25th percentile), and his head circumference was $47.5 \mathrm{~cm}$ (60th percentile). His facial features appeared somewhat dysmorphic with a prominent forehead and eyes having an antimongoloid slant. His anterior and posterior fontanelles were soft. His nails and dentition were normal.

The skin was hyperpigmented at the nape of the neck (a feature present since birth), and hyperpigmented in spots over both knees, the left shin, and right trunk. The skin over the trunk and feet was tight, and there was limited range of motion at the ankles, presumably because of the tight skin. The skin over the temporal region was thin with prominent appearing veins (Figs. 1 and 2).

Ophthalmologic examination was normal. Laboratory investigations were normal and included RA factor, anti-nuclear antibodies, amino acid screen in urine, serum calcium, phosphorous, aldolase, cholesterol, $\mathrm{T}_{3}$ resin uptake, and $\mathrm{T}_{4}$ RIA. A biopsy of axillary skin was reported as having no pathologic diagnosis, although the elastic fibers were prominent. An additional biopsy was recommended, but not performed.

At age 3 years 3 months, the child was evaluated for a painful left hip and a limp of 4 to 5 months duration. On physical examination, his range of motion was limited. A radiograph of his pelvis was consistent with a diagnosis of aseptic necrosis of the left capital femoral epiphysis. Eight months later, he complained of right hip pain. A radionuclide bone scan showed a photopenic area in the right hip suggestive of early avascular necrosis. The skin over his hands and feet was noted as being thin and tight. His hair was observed to have become coarser and thinner than noted in the past. He also appeared to have midfacial duskiness and a sculpted tip of the nose, as well as a pointed chin.

\section{Radiographic findings}

Skeletal survey was performed at 14 months of age. The child's skeletal maturation was normal for his chronologic age. The cranial sutures were wide and multiple wormian bones were seen in the lambdoidal sutures. There were linear lucent defects in the proximal tibial metaphyses, left proximal femoral ditaphysis, and right proximal humeral metaphysis. There was acro-osteolysis of the terminal phalanges of digits 2 and 5 of the right hand; digits 2, 3, and 5 of the left hand; digits 1,2 , and 3 of the left foot; and digits 1,2, and 3 of the right foot. There was a slight, bilateral hallux valgus deformity. Both humeri appeared somewhat shortened, with relatively broad metaphyses and diaphyses (Fig. 3).

A repeat skeletal survey was performed at 4 years 8 months of age. The cranial sutures remained open, and wormian bones in the lambdoidal sutures were still present (Fig. 4). The mentum of the mandible was prominent, and there was antegonial notching of the mandible. The linear lucent defects in the long bones were unchanged (Fig. 5). There was bilateral varus deformity of the femurs. There was aseptic necrosis of the left hip with remodelling of the acetabulum (Fig. 5).

The bone age was normal based on develop- 

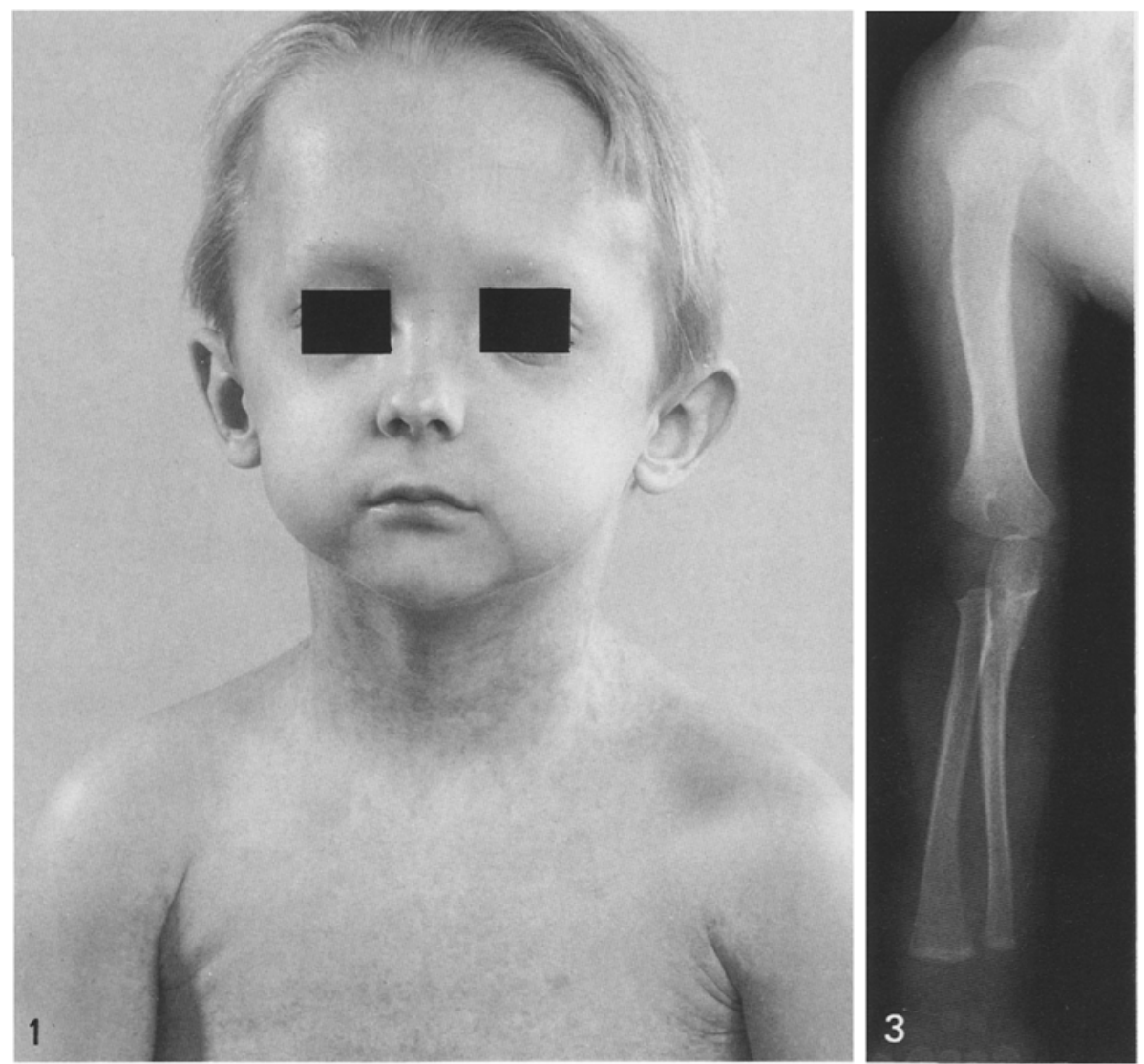

Fig. 1. The chin is pointed, the nasal tip is glyphic, and tight, hyperpigmented skin is seen over the neck and shoulders

Fig. 2. Tight, hyperpigmented skin is seen over the trunk and elbows

Fig. 3. The humerus is somewhat short, and the diaphysis appears broad

Fig. 4. Delayed closure of the cranial sutures is noted with wormian bones. The mentum of the mandible is prominent and there is antegonial notching
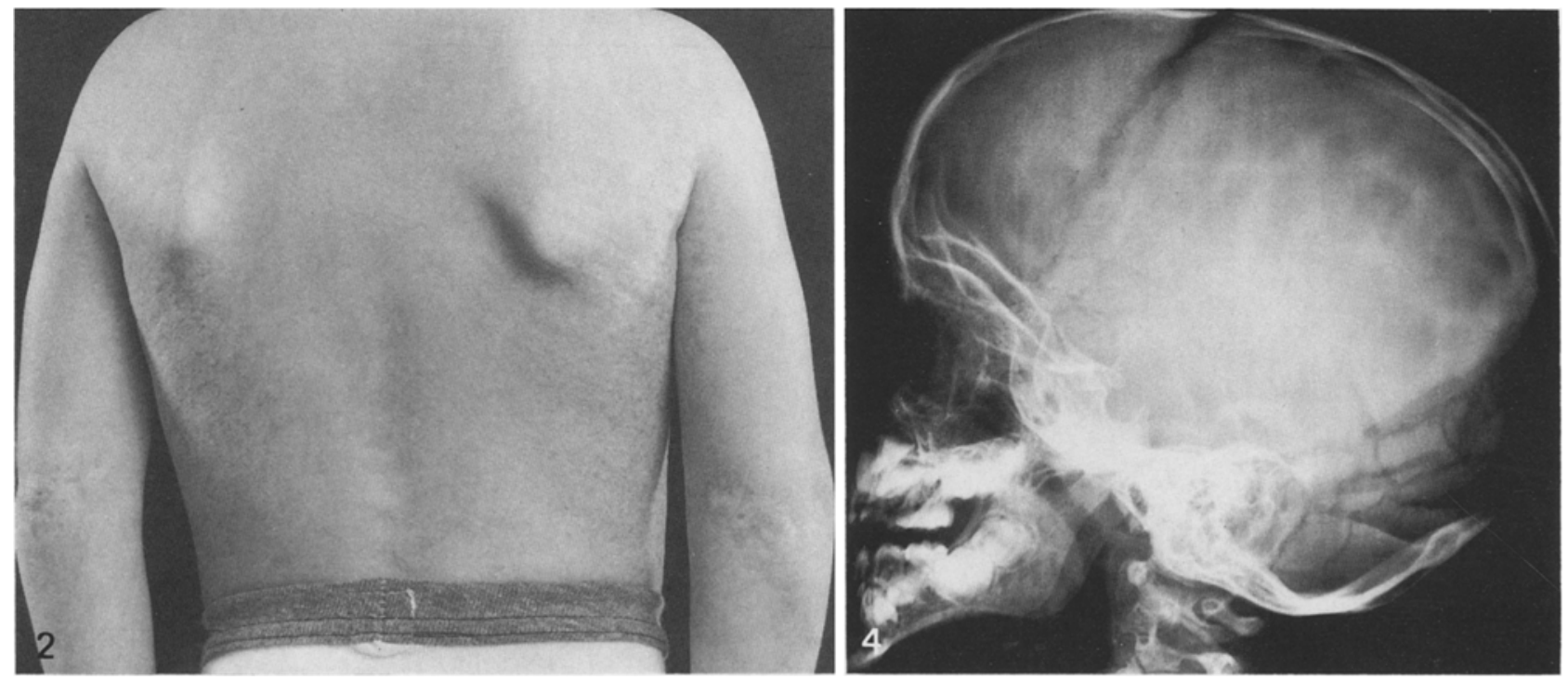

ment of the phalangeal ossification centers, but there was delay in ossification of the carpal centers. There was acro-osteolysis of the terminal phalanges of digits 2 and 5 of the right hand; digits 2 , 3 , and 5 of the left hand; digits 1,2 , and 3 of the right foot; and digits 1,2 , and 3 of the left foot (Figs. 6 and 7). Ossification was absent in the epiphyses of the 4th metacarpal of the right hand and the 3rd and 4th metacarpals of the left hand.

\section{Discussion}

Our patient exhibited some of the typical clinical features of acrogeria including relatively short stat- 

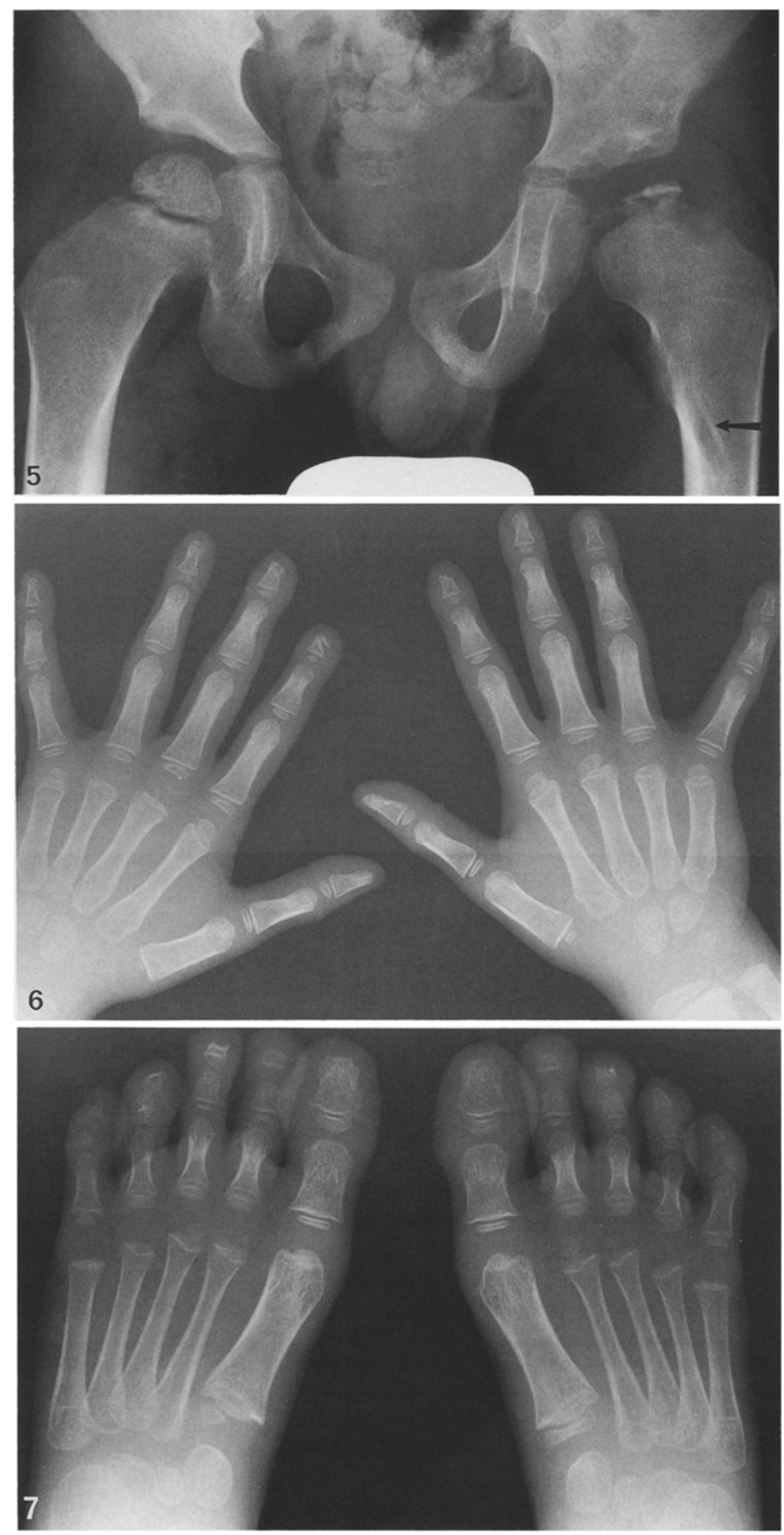

Fig. 5. Lucent linear defect is seen in the left femoral ditaphysis (arrow). Aseptic necrosis of the left capital femoral epiphysis is seen

Fig. 6. Acro-osteolysis of the distal phalanges of the hands is present

Fig. 7. Acro-osteolysis of the distal phalanges of the toes is present 
Table 2. Radiological findings in acrogeria and progeria

\begin{tabular}{lcc}
\hline & Acrogeria & Progeria \\
\hline Acro-osteolysis of terminal tufts & + & + \\
$\begin{array}{lll}\text { Hypoplasia of mandible } \\
\quad \text { micrognathia) }\end{array}$ & + & + \\
$\begin{array}{ll}\text { Hypoplasia of maxilla } \\
\text { Hypoplasia of ribs }\end{array}$ & - & + \\
Hypoplasia of clavicles & - & + \\
Progressive osteolysis of & - & + \\
$\quad$ hypoplastic bones & - & + \\
Generalized osteoporosis & & \\
Wormian bones in skull & - & + \\
Open fontanelles & + & + \\
& + & + \\
Abnormalities in long bones: & & \\
Broad, poorly tubulated metaphyses & + & + \\
Gracile bones & + & + \\
Coxa valga deformity & + & + \\
Constricting lesions in humeri & - & + \\
Tubular lucencies in long bones & + & + \\
Legg-Perthes disease & + & + \\
\hline
\end{tabular}

ure, tight pigmented skin over the hands, feet, and trunk, a pointed chin and nose, and midfacial duskiness. The skeletal features noted in this patient included acro-osteolysis, delayed closure of cranial sutures, wormian bones, lucent metaphyseal defects, and antegonial notching of the mandible.

There are many similar skeletal abnormalities that are seen both in progeria and acrogeria (Table 2) $[21,28,31]$. Clinically, both conditions appear similar. The facies are remarkable for midfacial duskiness and a glyphic nasal tip, and the thin skin resembles the changes associated with scleroderma [7]. In progeria, hypoplasia of the clavicles and ribs has been observed to progress to complete osteolysis, a finding which has not been seen in acrogeria [26]. Margolin and Steinbach have also observed progressive resorption of the terminal phalanges of the hands and feet [22]. Although our patient is only $41 / 2$ years old and has been observed for a short period of time, progressive acro-osteolysis was not seen. Another significant skeletal finding in progeria is osteoporosis, which has been described clinically, radiologically, and histologically $[9,29]$. This is consistent with the generalized premature aging seen in these patients who are at increased risk of developing myocardial infarcts and cerebrovascular accidents. The bone density is normal in all the cases of acrogeria reported with the exception of Volpato's case which had slight demineralization [32]. Another curious finding in progeria are constricting lesions in long bones; the humerus is especially prone to fracture [26]. No pathological fractures have been reported in acrogeria. Our patient had a bony fragment adjacent to a resorbed phalangeal tuft in the index finger of the left hand which could possibly represent a pathological fracture through abnormal bone. It could, however, simply represent the particular pattern of acro-osteolysis in this patient.

In their reported case of progeria, Ozonoff and Clemett described central lucent defects in each tibia. They compared these defects to large vascular foramina [26]. Our patient had tubular lucencies in the left proximal femur, proximal tibias, and proximal humeri similar to those seen in dyschondroplasia and enchondromatosis. These lucencies have been described as cartilaginous rests.

The orthopedic problems in progeria have been well documented $[10,24]$. A marked delay in bone healing or nonunion after fractures, particularly at the sites of resorbed bone, has been noted. Autopsy specimens reveal replacement by fibrous tissue in the areas of osteolysis [24]. Avascular necrosis of the hips has been observed in progeria [6, 24], but it occurred around 9 or 10 years of age, which is normal for this idiopathic condition. Our patient developed symptoms of avascular necrosis in one hip at age $21 / 2$ to 3 years; involvement of the opposite hip occurred the following year. We believe that this relatively early presentation of avascular necrosis is unusual and may be due to an underlying cartilaginous defect related to abnormal collagen. Moen has noted that, in progeria, coxa plana develops at an early age (usually by age 5 years). He suggests that avascular necrosis is the underlying etiology [24]. Only two other cases of acrogeria had hip abnormalities and both were described as congenital dislocated hips $[8,17]$.

Other entities besides progeria need to be distinguished from acrogeria. Arthrodento-osteodysplasia or Hajdu-Cheyney syndrome has skeletal features similar to acrogeria, including wormian bones, delayed cranial suture closure, small mandible, and acro-osteolysis. However, those affected with Hajdu-Cheyney syndrome are reported to have joint laxity, as opposed to the limitation of joint mobility associated with the tight skin of acrogeria. Pycnodysostosis, mandibuloacral dysplasia, and cleidocranial dysostosis all share features seen in acrogeria, the most notable being acro-osteolysis. The similarity of skeletal findings suggests that all these disorders may share a common mesodermal defect of development.

In conclusion, acrogeria, a little known entity except among dermatologists, has clinical and radiological features most similar to those seen in progeria. The latter disease is an extremely rare, but important, differential diagnosis because of its 
poor prognosis, with death expected in the second or third decade of life [7]. It is vital to distinguish acrogeria from progeria as none of the cases of acrogeria, although the number is small, have progressed to the same fatal result. Acrogeria has been defined as a dermatological defect confined to the dermis and subcutis [16]. In their article, Groot et al. concluded that it may be another example of a widespread heritable disorder of connective tissue chiefly affecting the cutis and subcutis [14]. Elefant et al. believed that there is a systemic insufficiency of connective tissue because of his additional findings of flattened skull, blue sclerae, transparent enamel, and hip joint dislocations [8]. In their study of the ultrastructure of the dermis, Laurent and Agache suggest that acrogeria may be a fibroblastic disease [19]. The skeletal findings of wormian bones, tubular lucencies in long bones, acro-osteolysis, and avascular necrosis of femoral capital epiphyses suggest that the condition affects the development of both membranous and cartilaginous bones. Acrogeria should be considered a generalized mesodermal abnormality that is not confined to the skin alone.

Acknowledgements. The authors would like to thank Dr. Franklin L. DeBusk for his advice in the evaluation of the patient here reported and Drs. Caroline Blane, Robert Cantor, Paul Capek, and Dietrich Roloff for their help in translating the foreign language references into English.

\section{References}

1. Batschvaroff B, Stanischeff D, Prikolotina M (1961) Ein neuer Fall von Akrogerie Gottron. Dermatol Wochenschr $143: 59$

2. Bazex A, Dupre A (1955) Acrogeria (type Gottron) Place de l'acrogeria dans le cadre des atrophies cutanees congenitales. Ann Dermatol Venereol 82:604

3. Bommer W, Kunzer W, Hauser W (1961) Krankheitsbild mit Zeichen einer Progerie und eines Erlos Danlos Syndroms. Arch Kinderheilkunde 165:172

4. Butenandt O, Christophers E (1970) Die Akrogerie (Gottron). Dtsch Med Wochenschr 95:175

5. Calvert HT (1957) Acrogeria (Gottron type). Br J Dermatol $69: 69$

6. Curtin VT, Kotzen HF (1929) Progeria. Review of the literature with a report of a case. Am J Dis Child 38:993
7. DeBusk FL (1972) The Hutchinson-Gilford progeria syndrome. J Pediatr 80:697

8. Elefant E, Vychytil O, Trapl J (1965) Acrogeria, a case report. Annal Paediatrici 204:273

9. Gabr M, Hashem N, Hashem M, Fahmi A, Safouk M (1960) Progeria, a pathologic study. J Pediatr 57:70

10. Gamble JG (1984) Hip disease in Hutchinson-Gilford progeria syndrome. J Pediatr Orthop 4:585

11. Gilkes JJH, Sharvill DE, Wells RS (1974) The premature aging syndromes. Br J Dermatol $91: 243$

12. Gottron H (1941) Familiare akrogerie. Arch Dermatol Syphilis $181: 571$

13. Gromzig H (1951) Über einen Fall von Akrogerie. Der Hautarzt 2:493

14. Groot WP, Tafelkruyer J, Woerdeman MJ (1970) Familial acrogeria (Gottron). Br J Dermatol 103:213

15. Gruneberg Th (1960) Die Akrogerie. Arch Klin Exp Dermatol $210: 409$

16. Hjortshoj A, Heydenreich G (1977) Acrogeria. A case report. Dermatologica 154:355

17. Lamy M, Frezal J, Nezelof C, Raverdy (1961) L'Acrogeria. Arch Fr Pediatr 18:18

18. Laugier P, Gomet CH, Woringer Fr (1959) Acrogeria (Gottron) et Keratose folliculaire serpingineuse. Bull Soc Fr Dermatol Syphiligr 66:80

19. Laurent R, Agache P (1974) L'Acrogeria est-elle une maladie du fibroblaste? Etude ultrastructurale. Dermatologica 148: 28

20. Levi L, Bellani G, Vergani C, D'Alonzo R, Fiorelli G (1970) L'acrogeria di Gottron. Ital Dermatol 105:645

21. Macleod W (1966) Progeria. Br J Radiol 39:226

22. Margolin FR, Steinbach HL (1968) Progeria, HutchinsonGilford syndrome. AJR 103:173

23. McKusick $\vee(1975)$ Mendelian inheritance in man. The Johns Hopkins University Press, Baltimore

24. Moen C (1982) Orthopaedic aspects of progeria. J Bone Joint Surg [Am] 64:542

25. Morris D (1957) Acrogeria. Proc R Soc Med 50:330

26. Ozonoff MB, Clemett AR (1967) Progressive osteolysis in progeria. AJR 100:75

27. Raffi A, Laurent R, Agache P (1972) Acrogeria de Gottron. Bull Soc Fr Dermatol Syphiligr 79:34

28. Reichel W, Bailey JA, Zigel S, Garcia-Bunnel R, Knox G (1971) Radiological findings in progeria. J Am Geriatr Soc 9:657

29. Reichel W, Garcia-Bunnel R, Dilallo J (1971) Progeria and Werners syndromes as models for the study of normal human aging. J Am Geriatr Soc 19:369

30. Rosenberg D, Monnet P, Moulin G, Gauthier J (1972) L'Acrogeria. La Medecine Infantile 79:231

31. Schwarz E (1962) Roentgen findings in progeria. Radiology $79: 411$

32. Volpato S (1961) L'Acrogeria. Fracastoro 54:457 